\title{
Aids e imprensa:
}

\section{escritos do jornal Folha de S. Paulo*}

\section{Rosana de Lima Soares ${ }^{1}$}

LIMA SOARES, R. Aids and the press: a narrative approach. Interface - Comunicação, Saúde, Educação, v. 2, n.2, 1998.

The present work aims to present narrative constructions about Aids published in 31 articles in the Brazilian newspaper Folha de S. Paulo in 1994 and 1995. The articles were selected out of random sample. Analysis of the texts was carried out based on the Sciences of Language, pointing out how the narratives about Aids are built. The following language theories were used during the analysis: F. Saussure's linguistics theory, A. J. Greimas's narration semiotics, C.-L. Strauss's ethnology and J. Lacan's Freudian psychoanalysis. These articles about Aids can be divided into three major groups: State, Science and Homosexuality. Each group involves a wide range of articles with different approaches which converge to two basic points: evil versus good. The disease and the sick are presented as having images of "sin" and "damage". Science is presented as the redeemer which freeds people from evil and is capable of "curing" and "saving". The basic structure of the narrative about AIDS is, therefore, impregnated with religious and mystic images, that is, sin and salvation, the sinner and the saved.

KEY WORDS: Aids; public health; narration theory

Este artigo busca apresentar as construções narrativas e discursivas sobre a Aids em 31 matérias publicadas no jornal Folha de S. Paulo durante os anos de 1994 e 1995, selecionadas a partir de uma amostra aleatória. A partir das teorias constituintes das Ciências da Linguagem (a teoria lingüística, a semiótica narrativa e discursiva a partir de A. J. Greimas, a etnologia e a psicanálise freudiana, na releitura de J. Lacan), a leitura dos textos jornalísticos desloca-se da área das Ciências Sociais para a área de confluência das correntes teóricas voltadas para a linguagem, indicando como estão construídas as narrativas sobre a Aids nos textos analisados. As análises indicam a configuração de três grandes grupos temáticos nas matérias estudadas: Estado, ciência $e$ homossexualidade. Cada um dos grupos engloba matérias com abordagens diversas, mas sua confluência se faz, finalmente, em dois grandes eixos: a oposição mal x bem, compondo a doença e o doente como recobertos por imagens de "pecado" e "dano", e a ciência como a redentora destes males, capaz de "curar" e "salvar". A estrutura básica do discurso da Aids reveste-se, assim, de configurações imaginárias relacionadas ao domínio do religioso e do místico: o pecado e a salvação, o pecador e o salvo.

PALAVRAS-CHAVE: Aids; Jornais, Meios de Comunicação de Massa, Saúde Pública

\footnotetext{
${ }^{*}$ Artigo desenvolvido a partir de pesquisa para dissertação de mestrado realizado junto ao Núcleo de jornalismo e Linguagem, do Departamento de Jornalismo e Editoração da Escola de Comunicações e Artes da Universidade de São Paulo (USP).

${ }^{1}$ Mestre em Ciências da Comunicação pela Escola de Comunicações e Artes da USP.
} 


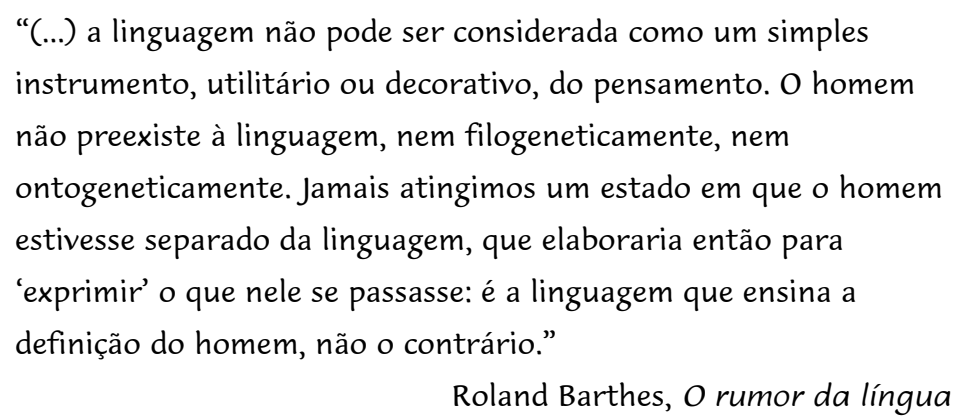

Muito já se sabe e muito já foi falado sobre a Aids. Apesar disso, os números ainda assustam: segundo estatística da OMS, em 1996 havia 20 milhões de pessoas contaminadas pelo HIV em todo o mundo. Poder-se-ia dizer, então: muito já se sabe, muito já foi falado e pouco tem sido feito.

A abordagem aqui ensaiada baseia-se na crença de que, no caso da Aids, a distância entre o que se sabe e o que se fala é ainda muito grande se comparada ao que realmente se faz, principalmente em termos de atitudes pessoais, mudanças de comportamento e prevenção.

Em uma sociedade bombardeada por informações, os assuntos muitas vezes se tornam banais antes de haverem sido realmente incorporados pelas pessoas. Com relação à Aids, observa-se um saturamento de informações e uma sensação de que o assunto já tenha sido bastante explorado. Entretanto, a maioria das pessoas continua agindo como se a doença não existisse. Passados os estágios iniciais de choque e pânico, acostumam-se à idéia da Aids, que, entretanto, continua se propagando silenciosamente.

A temática deste artigo, portanto, surgiu de uma preocupação genuína com relação à Aids, doença complexa que tem formas peculiares de transmissão e está se propagando com rapidez assustadora, mesmo agora que já se tem um número razoável de informações sobre ela. As construções narrativas da imprensa com relação à doença serão abordadas buscando esclarecer alguns dos mecanismos envolvendo o desgaste do assunto Aids antes mesmo de se haverem operado mudanças significativas na sociedade, e responder porque a doença se configurou da forma como o fez, com as resistências e preconceitos dos quais se reveste.

A particularidade da Aids enquanto doença faz com que ela seja não apenas um assunto médico e científico, mas também psicossocial e cultural, com grandes implicações em termos de educação. Mas os avanços em termos de prevenção $e$ 
2 Até agora, as pesquisas científicas e os avanços médicos indicam que a descoberta da cura da Aids ou o desenvolvimento de uma vacina eficaz ainda estão longe de serem concretizados. Esforços para prevenção da doença são, assim, a única possibilidade concreta de deter sua disseminação a curto prazo.

3 Sergio Haddad (1993), ao se referir à "cultura de prevenção" esclarece: "O trabalho educativo é prioritário na questão da prevenção da Aids. Mas esta educação, para ser eficaz, deve ser adequada às diversas faixas etárias, a grupos sociais específicos, aos homens $e$ mulheres, seus hábitos, comportamentos, valores éticos e culturais". controle não correspondem aos avanços já alcançados pela ciência ${ }^{2}$, que embora não tenha ainda encontrado uma cura ou vacina eficaz avançou significativamente em termos de conhecimentos sobre esta doença nos últimos anos.

Mesmo entre aqueles que possuem informações a respeito da Aids não ocorrem, necessariamente, mudanças de comportamento e atitude devido a ela. O trabalho de prevenção torna-se mais complexo do que parece: não basta informar, é preciso criar e ampliar uma "cultura de prevenção"3 para tentar equilibrar a diferença existente entre o volume de informações sobre a doença $e$ a pouca assimilação de práticas de prevenção entre a maioria das pessoas. Apesar da relativa "banalização" da questão da Aids, o número de casos de pessoas contaminadas aumenta em progressão geométrica, indicando a existência de um hiato entre possuir uma informação e empreender a ação.

Foi a partir desse hiato que se desenvolveram as considerações agora apresentadas. Se informação não é sinônimo de prevenção, restava procurar em outro lugar uma possibilidade para pensar a questão da Aids. Tal possibilidade foi encontrada no campo teórico das ciências da linguagem. Concebendo a linguagem como fundante do humano e, assim, da própria realidade - por meio dos discursos que a organizam -, as ciências da linguagem possibilitam pensar a Aids a partir de sua organização narrativa, entendendo narrativa como o imaginário que impregna o discurso, lugar do simbólico, passando a determinar as construções sociais sobre a doença. A partir dessa concepção, a Aids passa a ser considerada não apenas enquanto fenômeno social, mas, sobretudo, como construção discursiva.

Um dos lugares privilegiados para acompanhar essa narrativa - não a narrativa construída sobre a Aids, mas a narrativa que a própria Aids foi construindo para si por meio dos vários discursos que foram criando o objeto Aids (discurso religioso, discurso da Ciência, discurso moral, discurso do Estado) - é o jornalismo. Assim, parte-se do pressuposto de que o discurso, enquanto criador de laço social (Lacan, 1966; 1985), foi instituindo a Aids como uma grande narrativa nos jornais.

A partir das ciências da linguagem, portanto, o jornalismo passa a ser considerado como uma estrutura da linguagem, e os jornais como ordenadores de discursos nos quais é possível destacar uma estrutura narrativa. Ao afirmar isso, o termo estrutura está sendo tomado em sua acepção mais clássica de um 
todo no qual é considerada a forma pela qual se dispõem as partes que o constituem, um todo no qual "uma coisa não vai sem a outra", uma articulação em cadeia, significando, ainda, que a soma das partes não perfaz um todo (Lévi-Strauss, 1974).

O desenvolvimento deste artigo configura-se, assim, num duplo movimento: por um lado, estuda a Aids para apreender os modos de operação do discurso jornalístico e, por outro, estuda o jornalismo como parte de algo que o transcende, extraindo dele o discurso da Aids. Com isso, pretende-se falar da Aids - entender sua própria narrativa - e do jornalismo - de suas formas de construção discursiva -, o jornalismo considerado como um local privilegiado para a articulação dos diversos discursos constituintes (e instituintes) da sociedade. É no universo dos escritos do diário paulistano Folha de S. Paulo que tal abordagem será proposta, buscando expandir os limites da doença em si e questionar o próprio papel e atuação do jornalismo enquanto articulador de discursos e, neste caso, de uma narrativa sobre a Aids.

Nesse momento, talvez essa tentativa, no fundo, seja simplesmente alguma tristeza em ver "todas essas pessoas preciosas morrendo antes do tempo, essas pessoas [que] não vão ser substituídas, e isso é uma perda tão grande (...) Parece ser assim que vivemos, assim que vivemos agora" (Sontag, 1995, p.39;19). Daí a idéia de traçar esse escrito sobre os escritos da Aids em um jornal diário de grande circulação. Uma tentativa de tentar apontar o que tem se cristalizado enquanto discurso sobre essa doença em um veículo que tem papel de construtor (com tantos outros) da arena simbólica da sociedade contemporânea (Gans, 1980).

\section{Aids: narrativas no jornal Folha de S. Paulo}

Ao traçar uma trama revelando de que forma a questão da Aids se articula numa grande narrativa tecida pelos discursos instituintes da sociedade, entre eles o jornalismo, este artigo pretende revelar uma grande narrativa sobre a Aids que vai se construindo pelos jornais a partir dos traços (pequenas narrativas) deixados na notícia enquanto produto cultural da linguagem (Schudson, 1995). Optou-se por trabalhar com um jornal diário a partir da convicção de que o jornalismo é uma das instituições sociais contemporâneas e, portanto, instituído $e$ instituinte, instituição na qual, das manifestações ali colocadas, algumas se cristalizam em significados. 
4 Dos 32 dias inicialmente selecionados, doze não trouxeram nenhuma matéria sobre Aids (seis em cada ano).
As 31 matérias analisadas (quadro I) foram extraídas do jornal Folha de S. Paulo entre os anos de 1994 e 1995, distribuídas em vinte dias (dez a cada ano) ${ }^{4}$. As matérias foram selecionadas aleatoriamente, a partir de uma amostragem abrangendo cada um dos dias da semana nos diferentes meses do ano, apresentando, assim, as variações diárias do jornal e estabelecendo semelhanças e divergências.

Entre as segundas-feiras e sextas-feiras, foi selecionada uma edição ao mês, totalizando doze para cada ano, da seguinte forma: primeira segunda-feira de janeiro, segunda terça-feira de fevereiro, terceira quarta-feira de março, quarta quinta-feira de abril, primeira sexta-feira de maio, e assim sucessivamente; para as edições dominicais, dividiu-se o ano em quatro trimestres (janeiro-março; abril-junho; julho-setembro; outubro-dezembro), sendo que foi considerado o primeiro mês de cada trimestre (quatro edições ao ano). Para cada um dos meses (janeiro, abril, julho, outubro) foi escolhida uma edição dominical, da primeira à quarta semana, respectivamente.

O jornal escolhido é publicado desde 1921 pela empresa Folha da Manhã. Nas últimas décadas, passou por processos profundos de renovação gráfica, incorporando, progressivamente, novos elementos a seu projeto visual e gráfico. A Folha publica regularmente matérias de divulgação científica, principalmente aquelas ligadas à área de medicina, descobertas científicas e saúde, o que explica a regularidade da publicação de textos sobre a questão da Aids:

\footnotetext{
De setembro de 1987 a dezembro de 1996, a Folha de S. Paulo publicou 7.074 matérias que, de alguma forma, faziam referência à Aids. Ao longo de quase uma década, foram duas matérias por dia. No ano passado, 1.550 reportagens trataram da doença, média de 4,24 matérias por edição referindo-se a algum aspecto da Aids (Biancarelli, 1997: 144).
}

A matéria mais antiga sobre Aids a que se teve acesso ("Congresso debate doença comum entre homossexuais") foi publicada no dia 03 de junho de 1983. Alguns de seus trechos são reproduzidos a seguir:

\footnotetext{
Uma doença que a literatura médica registrou somente em 1981 e tem incidido com maior freqüência entre a população homossexual dos Estados Unidos, ocupou a maior parte dos trabalhos matinais do $2^{\circ}$ Congresso Brasileiro de Infectologia, que se encerra neste domingo, no Maksoud Plaza.
} 
Uma exposição sobre essa doença - conhecida como o "Síndrome da Imunodeficiência Adquirida”, ou simplesmente AIDS (Acquired immunne deficiency syndrome) - foi feita pelo médico norteamericano Warren Johnson, do hospital de Nova York, que ao apresentar dados sobre a alta taxa de mortalidade provocada por essa síndrome lamentou as dificuldades encontradas para combatê-la. Até agora, disse, "nem mesmo foi possível localizar o agente que a causa".

(...) Diante de uma atenta platéia com perto de 500 pessoas, Warren Johnson apresentou diversos dados levantados nos Estados Unidos, explicando que o aspecto clínico do paciente costuma evidenciar no início alguns sintomas leves - como febre, fadiga e falta de ar -, evoluindo posteriormente para infecções múltiplas. Sem imunidade para combater essas infecções, cerca de $50 \%$ dos pacientes acabam morrendo seis meses depois de diagnosticada a doença. A multiplicidade de infecções, acrescentou, dificulta ainda mais seu combate, aumentando o índice de mortalidade com o decorrer do tempo. Calcula-se que em dois anos deverão morrer $85 \%$ das pessoas que tiveram diagnosticada a doença a partir de 1979.

(...) Além da população homossexual - na qual se registram $71 \%$ dos casos conhecidos nos Estados Unidos -, também junto aos dependentes de drogas ingetadas (sic) por vias intravenosa verificase uma incidência acentuada (Folha de S. Paulo, 03/06/83).

Após essa primeira aparição, foram publicadas as seguintes matérias com referências diretas ou indiretas à Aids (grifos da autora): "Congresso termina com crítica de médico ao Inamps" (06/06/83), “Aids já preocupa países europeus" (06/07/83), "Programa contra Aids começa amanhã” (04/09/83), "Programa contra a Aids iniciado por Secretaria" (06/09/83), "Prevenção da Aids" (07/11/83), "Vírus da Aids espalha-se pelo mundo, advertem os cientistas" (11/12/84), nenhuma delas assinada por um jornalista específico.

O que se destaca nessas primeiras matérias é o fato de que alguns elementos nelas cristalizados permanecem até os dias de hoje. Entre eles, destacam-se as referências aos homossexuais (na matéria de 06/06/83, por exemplo, a expressão doença de homossexuais é usada como sinônimo de Aids) e aos usuários de drogas, o tom alarmista das matérias demonstrando que a ciência - que tudo 
sabe - não sabia sobre a doença e, de início, nem sobre seu agente transmissor, a idéia de que a doença "espalhava-se" pelo mundo, a imagem da doença como um "mal a ser combatido".

Foi assim que a Aids começou a escrever sua história nos primeiros escritos publicados na Folha de S. Paulo. São apresentadas, a seguir, as leituras das matérias publicadas onze e doze anos depois dessas primeiras notícias.

\section{Por um modo de ler}

O desenvolvimento do tema proposto - relacionar Aids e jornalismo identifica o discurso articulador construído por meio da grande narrativa da Aids escrita pela imprensa, discurso esse impregnado por todas as construções imaginárias que cercam esta doença.

A leitura das matérias fundamentou-se no capítulo de Émile Benveniste (1989) que trata do "aparelho formal da enunciação". Enunciação, palavra-chave neste momento: ler não o texto dos enunciados (das matérias), mas o como foram escritos, sua enunciação. A enunciação seria este "colocar em funcionamento a língua por um ato individual de utilização" (Benveniste, 1989, p.82). Dessa forma, “(...) é o ato mesmo de produzir um enunciado, e não o texto do enunciado, que é nosso objeto. Este ato é o fato do locutor que mobiliza a língua por sua conta. A relação do locutor com a língua determina os caracteres lingüísticos da enunciação" (Benveniste, 1989, p.82) (grifos da autora).

De acordo com Benveniste, todas as línguas têm em comum determinadas categorias, das quais destaca as de pessoa, espaço e tempo. A categoria pessoa é organizada em duas oposições básicas: o eu em oposição ao tu (“não-eu”), e a pessoa eu ou tu em oposição à não-pessoa ele. $\mathrm{O}$ eu coloca-se como interior ao enunciado e o tu como exterior, podendo ter seus lugares invertidos, o eu podendo sempre tornar-se tu e vice-versa. A não-pessoa ele, entretanto, não pode nunca inverter-se em pessoa (eu ou tu).

$\mathrm{O}$ eu é "a pessoa que enuncia a presente instância de discurso a conter a instância lingüística eu” (Barthes, 1988, p.34). Ao falar, portanto, o eu assume o lugar daquele que, naquele momento diz "eu", o outro podendo requerer para si 
a posição de eu, falando, a seu termo, "eu". O eu da língua só se constitui a partir daquele que o fala. Em relação ao espaço, ou "lugar do fato", este colocase como próximo ou distante do locutor, aquele que fala.

A categoria do tempo, por sua vez, é tida por Benveniste como uma das mais ricas da língua. Antes de tratar especificamente do tempo lingüístico, Benveniste aponta para a distinção que se deve fazer entre o tempo físico, um contínuo uniforme, linear e infinito que pode ser segmentado de diferentes formas, o tempo crônico (ou cronológico), tempo dos acontecimentos e do desenrolar da história, e o tempo da língua. O tempo lingüístico, afirma Benveniste, tem seu centro no presente da instância da fala.

Pessoa, espaço e tempo são aqui considerados como referências intradiscursivas, apontando para as relações estabelecidas entre o enunciador (ou locutor) e a enunciação, criando, no enunciatário (ou interlocutor) uma relação de proximidade (categorias do eu-aqui-agora) ou distanciamento (categorias do ele-lá-então) com a enunciação.

A enunciação, propõe Benveniste, deve ser estudada sob três aspectos: a) a realização vocal da língua, seus sons e variedade fonética (que se verifica mesmo entre falantes de uma mesma língua); b) os mecanismos de sua produção, ou seja, analisar como o "sentido" se forma em "palavras"; c) definindo-a no quadro formal de sua realização.

O terceiro aspecto - definir a enunciação no quadro formal de sua realização foi privilegiado para a realização das leituras das matérias. Assim, foram considerados, na enunciação, três aspectos: a) o ato mesmo de produzi-la (ato individual pelo qual se utiliza a língua e que introduz o locutor como parâmetro nas condições necessárias da enunciação); b) as situações e condições nas quais ela se realiza (no caso desta análise, as determinações do fazer jornalístico); c) os instrumentos de sua realização.

Por meio de uma série de "indicadores", buscou-se, assim, construir o mecanismo de referência no processo de enunciação, entendendo a referência como parte integrante deste processo. É importante destacar que, entretanto, a referência não se dá em relação à realidade, mas aos discursos que se organizam para construí-la. Assim, para cada uma das matérias buscou-se indicar, além de seus elementos constituintes, os discursos por elas mobilizados (por exemplo, discurso da ciência, do Estado, médico, religioso, entre outros). 
Pelos vários discursos que são ali entrelaçados, o jornal cria com o leitor um universo referencial que este antes desconhecia. No caso da Aids, por exemplo, o lugar destinado pelo locutor à doença ou ao portador, ao nomeá-los, cria, para o leitor, um universo referencial determinado a partir dos diversos discursos ali chamados para construí-lo. Como parte das leituras das matérias de jornal, portanto, foram também identificados, além dos protagonistas da narrativa, os lugares em que o portador tem sido colocado pelo locutor.

Além destes elementos, destaca-se, do texto de Benveniste, a distinção realizada entre as diversas funções sintáticas da enunciação, empregadas pelo enunciador para influenciar de algum modo o comportamento daquele a quem se dirige. A asserção, "a manifestação mais comum da presença do locutor na enunciação" (Benveniste, 1989, p.86), parece ser a função sintática mais recorrente no discurso jornalístico, já que jornal visa comunicar uma certeza, seja ela afirmativa ou negativa. Um bom exemplo disto são as manchetes publicadas, como será visto na parte específica sobre as matérias analisadas, invariavelmente assertivas.

Finalmente, buscou-se, ainda, observar isoladamente os títulos de cada uma das matérias e, em sua construção narrativa, as palavras ou imagens recorrentes, repetidas nas matérias em relação a si mesmas e nas matérias umas em relação às outras.

Como última observação, é importante reforçar a questão do outro implicada em qualquer forma discursiva. Da enunciação, Benveniste afirma:

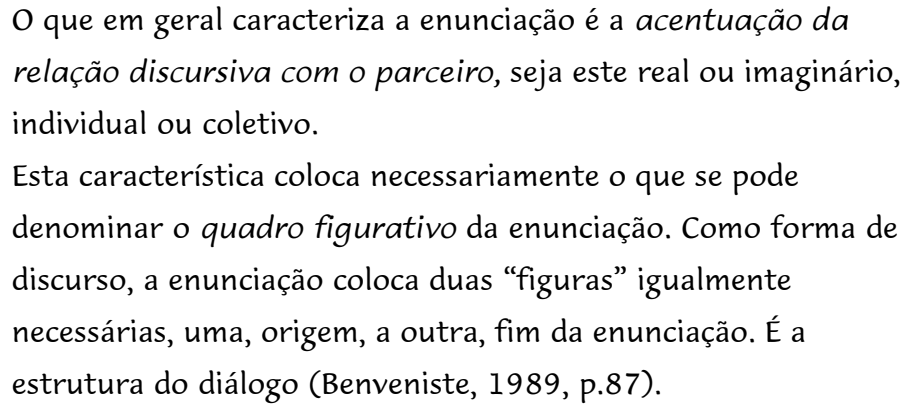

No discurso jornalístico, mesmo que este seja considerado um vasto monólogo do jornalista (ainda que não do mesmo jornalista em todos os momentos), o outro, pressuposto em qualquer enunciação deve, necessariamente, estar lá colocado, um "eu locutor" que se opõe a um "eu leitor". 
A partir desses parâmetros, organizaram-se quadros figurativos da enunciação. Considerou-se, portanto, que o que surge no discurso são formas figurativas que formam o quadro da enunciação. No caso das matérias de jornal, buscou-se destacar quais figuras aparecem para formar o quadro figurativo que caracteriza a Aids e o portador do HIV, quais as referências que vão constituindo a enunciação quando se fala da Aids. É este quadro figurativo - que não é fixo, mas vai se modificando constantemente - que configura o imaginário da Aids. A enunciação, por meio dos discursos, instaura o lugar da Aids (e de todas as outras realidades discursivas) na sociedade. É desse lugar instaurado que se trata a seguir, uma breve tentativa de captar seus principais desvelamentos.

\section{Leituras das matérias}

O fazer jornalístico reveste-se, ele mesmo, de características próprias que determinam as relações do jornalista com a enunciação. A fala do jornalista já é, desde sua constituição, barrada e restringida pelas regras do fazer jornalístico. Entretanto, a posição do jornalista é determinada pelo discurso que articula a própria instituição, situando-o no lugar daquele que "pode dizer" e "tudo dizer" (o discurso do poder, o discurso do saber). Seria, assim, uma articulação de enunciados que atuam "como se" não partissem do lugar da enunciação.

No processo de leitura das matérias jornalísticas foi considerado como ponto fundamental o fato de que apesar de o discurso restringidor do jornal constituirse sobre a negação, o sujeito da enunciação ali aparece, emergindo. Ocorre, assim, uma "mistura" dos sujeitos: o sujeito da enunciação do discurso do jornal e o sujeito da enunciação que marca o próprio jornalista. Às vezes, esta relação causa estranhamento e desconforto; nestes momentos, coloca-se um paradoxo: apesar do sujeito da enunciação do jornalista se sobrepor, em determinadas ocasiões, ao sujeito da enunciação do jornal, ele busca, todo o tempo, não se deixar aparecer, negando a impossibilidade de "tudo dizer".

O jornalismo, portanto, pressupõe que seu fazer seja pautado por um "Eu, jornal..." (linguagem jornalística) falando com "Tu, leitor..." de uma terceira pessoa "ele", alguém distante, "lá". No caso da Aids, a linguagem jornalística estaria falando ao leitor das matérias e àqueles por ela afetados. Entretanto, o 
que não pode ser desconsiderado é que esta escrita, antes de ser expressão da Aids ou do jornal, é expressão daquele que fala (ou daquele que escreve), neste caso o próprio jornalista.

Enquanto escritor, o jornalista se enuncia escrevendo, e estrutura o que escreve. Assim, a enunciação escrita, que se distingue da falada, pode ser situada em dois planos: "O que escreve se enuncia ao escrever e, no interior de sua escrita, ele faz os indivíduos se enunciarem" (Benveniste, 1989, p.90). Com Freitas, afirmamos que

\footnotetext{
A direção proposta para as pesquisas aqui desenvolvidas, valendose da psicanálise freudiana e da antropologia estrutural, principalmente referidas aos trabalhos de Lacan e Lévi-Strauss, permitiu o deslocamento da figura do emissor da exterioridade das mensagens para o interior mesmo das produções discursivas. Nesse interior, o emissor não é aquele que fala, mas aquilo que do dito envia ao dizer, aquilo que, da mensagem, envia ao mensageiro (Freitas, 1997, p.21).
}

Ao escrever, portanto, o jornalista se enuncia e faz aqueles de quem escreve se enunciarem, não autonomamente, mas a partir de sua própria enunciação. A Aids, assim, enunciar-se-ia a partir desta fala, barrada, do jornalista que sobre ela escreve. Resta saber, portanto, quem fala pela fala do jornalista-narrador, aquele que efetivamente está escrevendo.

$\mathrm{Na}$ análise das matérias para configuração dos quadros figurativos, além de destacar os elementos acima apontados, três questões básicas em relação ao tema da Aids foram mantidas como motivadoras das leituras:

- Como o mundo entra em contato com a questão da Aids por meio dos jornais (como ela está escrita)?

- Como os discursos instituídos (referências) entram em contato com a questão da Aids (como a ela se referem)?

- O que dizem os discursos instituídos?

Analisando as características gerais encontradas nas matérias, as repetições, os temas e a composição de cada uma delas, optou-se por destacar alguns de seus aspectos gerais, já que a reprodução integral de todas seria, neste momento, fastidiosa e até mesmo contraproducente, dados os limites deste artigo. Trata-se 
portanto de estabelecer uma abordagem mais abrangente, que aponte não para a leitura individual das matérias mas para uma possível configuração da "grande narrativa" nelas escrita.

Uma primeira observação diz respeito aos títulos encontrados. Em sua maioria, as manchetes foram escritas em tempo presente, modo indicativo, de forma assertiva afirmativa. Apenas duas matérias trouxeram formas negativas do verbo ("A pílula não é para todos"; " $47 \%$ dos gays não usam preservativos") e em três matérias não há uso de verbos nos títulos. Estes elementos, considerados em relação à própria linguagem jornalística, apontariam para um dado interessante: o desejo de estabelecer, com o leitor, a idéia de que, no jornal, não há espaço para dúvidas ou equívocos, apenas para fatos já consumados e constatados. Entretanto, as certezas (em sua maioria positivas) apregoadas pelas manchetes nem sempre se confirmam na leitura das matérias.

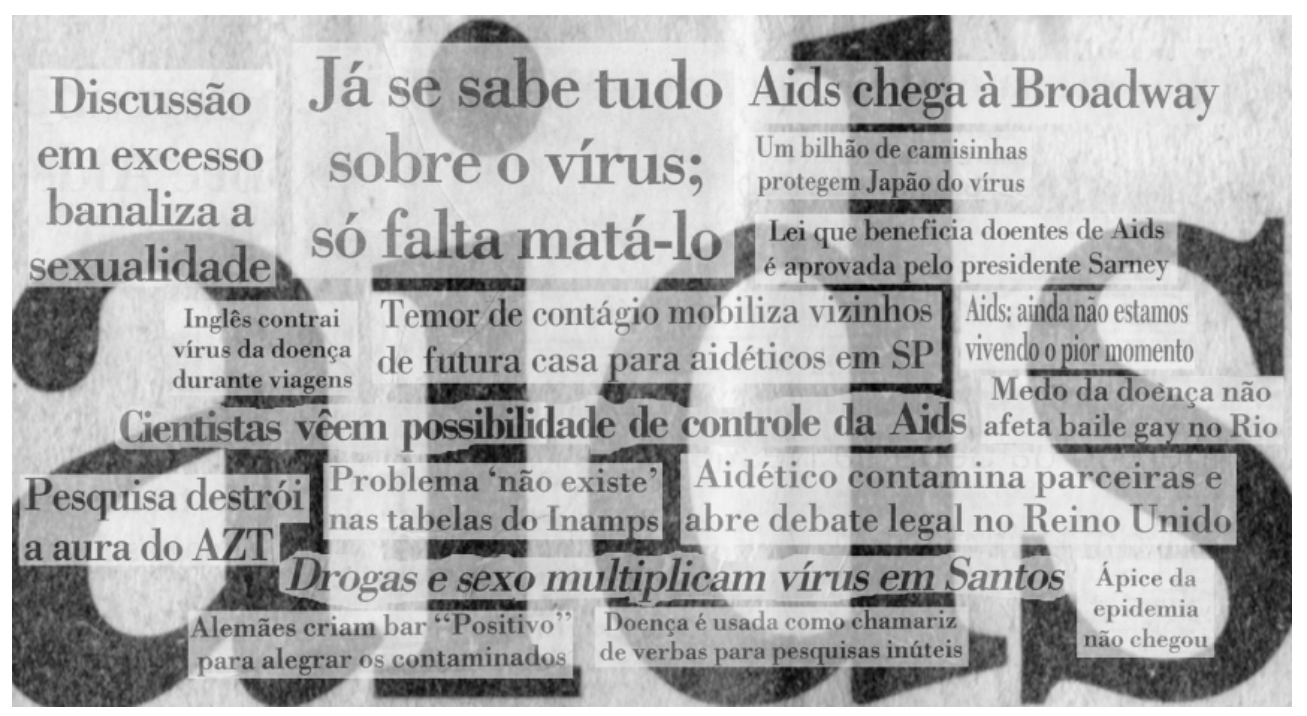

As matérias são escritas geralmente em terceira pessoa (singular ou plural), numa tentativa de conferir objetividade e neutralidade ao texto. As exceções ficam por conta de matérias assinadas por articulistas regulares do jornal, publicadas em suas respectivas colunas fixas. Em relação ao espaço, assim como para pessoa, a tentativa é transmitir objetividade e neutralidade ao leitor (o que, 
supostamente, conferiria maior credibilidade ao jornal). Dessa forma, o "lá", $e$ não o "aqui", é evocado como lugar dos fatos narrados.

A categoria tempo reveste-se de características variadas. Não se pode dizer que há predominância em termos de tempo verbal, presente, passado e até mesmo futuro (em menor grau) mesclando-se nas matérias e, algumas vezes, dentro da mesma matéria. Entretanto, como uso mais comum, pode-se colocar presente e passado como os tempos mais recorrentes, confirmando a estrutura narrativa à qual foi associado o jornalismo. Quanto aos modos do verbo, há clara predominância do indicativo, com alguns usos ocasionais do subjuntivo, quando se quer interpelar mais diretamente o leitor, e do condicional.

Entre os pronomes e advérbios, há usos variados, os advérbios sendo utilizados mais freqüentemente que os pronomes, principalmente para precisar a relação espácio-temporal apontada por Benveniste. "Ontem”, "hoje”, "pouco", "muito", "não", "nada" são advérbios comumente usados. É interessante notar que palavras que denotam dúvida ou incerteza, como "talvez" e "provavelmente", não aparecem com freqüência. Entre os pronomes, destacam-se os demonstrativos ("este”, “aquele”, “isto", “isso", “esse”, "essa”) e os pessoais. Chamou a atenção o fato de que nas matérias mais rigidamente ligadas à linguagem jornalística há pouco uso de pronomes pessoais, o sujeito de quem se fala sendo sempre nomeado, geralmente com uso de sinônimos (para cientistas, por exemplo, variações com as palavras pesquisadores, estudiosos, professores).

Em relação aos discursos instituídos chamados a configurar o discurso da Aids, destacaram-se os seguintes como aqueles mais evocados: discurso médico, discurso da ciência, discurso do Estado (englobando o discurso jurídico e o político) e o discurso social (englobando o discurso moral). Os demais foram variados, mas aparecendo poucas vezes. Entre eles, pode-se destacar: discurso literário; discurso religioso; discurso mediático (jornalismo, publicidade, televisão); discurso sociológico; discurso estético-cultural; discurso empresarial.

Os discursos médico e científico aparecem mais nas matérias diretamente ligadas à Aids, em forma de prevenção ou descobertas e pesquisas científicas. Ao utilizar nomes de pesquisadores, depoimentos e dados quantitativos, conferem verossimilhança e credibilidade à matéria. O discurso do Estado, quando evocado, parece sempre querer impor a lei e a ordem, chamar ao bom funcionamento da sociedade seja por meio de intervenção direta, seja por meio de mudanças na 
legislação e políticas públicas, principalmente ligadas à área de saúde. Finalmente, o que se chamou de discurso social engloba um espectro variado de elementos, desde manifestações de ONGs e grupos organizados (principalmente com reivindicações em relação à Aids e aos homossexuais) até expressões mais moralistas de grupos que clamam pelo que poderia ser chamado de "restabelecimento da ordem moral" da sociedade.

Em relação à Aids, apesar da variedade de aparições, um fato a ser destacado é o grande número de evocações em matérias que não tratavam diretamente do tema. Isto pôde ser percebido em diversos momentos, como em matérias que tratavam de cinema (o filme Morango e chocolate), de filosofia (o tema da felicidade), de tendências de comportamento sexual (da sociedade americana). Outras matérias, como aquelas sobre políticas de convênios, saúde pública $e$ drogas, apesar de não tratarem especificamente da Aids, apresentam caminhos mais nítidos para evocação da doença, apesar destes caminhos nem sempre parecerem indispensáveis à matéria.

As relações Aids-esquecimento, Aids-doenças mentais, Aids-exceção na lei, Aidsuso humanitário, Aids-privacidade, Aids-vida/morte, Aids-solidão, Aidsressecamento foram algumas das imagens evocadas a partir das narrativas escritas.

Quanto aos portadores do HIV, sintomáticos ou assintomáticos, as imagens evocadas para constituí-los não diferem muito daquelas referidas à própria doença. O termo "aidético", por si só revestido de conotação negativa, é usado freqüentemente nas matérias do jornal, marcando de forma rígida a distinção entre aqueles que têm Aids e aqueles que não vivem com ela.

Apenas quando as matérias se referem à possibilidade de contrair o vírus, mas sem tratar de pessoas ou situações específicas, é que a configuração do portador se faz de forma menos negativa ou pejorativa, por exemplo, quando se menciona a legislação inglesa que permite que estrangeiros residam no país "se o parceiro inglês tiver Aids", ou quando se fala em medicamentos que precisam ser testados "por soropositivos assintomáticos". Nas vezes em que o tema da matéria indica situações extremas, ligadas ao perigo, ao preconceito ou à morte, o "ser portador", "estar com Aids", "ter Aids" é recoberto por outras imagens.

A título de exemplo, na matéria "Atualidade determina o preço de ser feliz" a felicidade de um soropositivo está ligada ao esquecimento da doença; na matéria 
"Morango e chocolate vinga sonho tropical", do portador diz-se que definha por dentro. Na matéria "Xuxa diz que aceita fazer teste de HIV", que trata da publicação por um jornal da notícia de que Xuxa estaria com Aids, "ser portador" aparece como algo extremamente indesejável e comprometedor, uma verdadeira acusação.

Um caso curioso ocorre em relação a uma das matérias publicadas na editoria Ciência, geralmente de tom mais neutro e impessoal. Na matéria "Água pode transmitir infecção a aidéticos", a palavra "pacientes" aparece mencionada inúmeras vezes (praticamente em todos os parágrafos), a começar do subtítulo "Estudo sugere origem de doença comum em pacientes". Usualmente, nas matérias sobre infecções ou medicamentos ligados à Aids os textos se referem mais a doentes, soropositivos, portadores, pessoas infectadas pelo HIV. A palavra pacientes, assim repetida, não pode deixar de evocar paciência, o que, muitas vezes, deles é pedido quando se trata de medicamentos ou infecções relacionados à Aids.

Outro caso único em suas características é a matéria "Justiça italiana caça imunidade penal de aidético". Além de trazer em seu título a palavra "aidético", e apesar de ter sido classificada como mais relacionada à legislação e ao Estado, confere, a todo momento, um aspecto notadamente degradante e negativo aos portadores dos quais trata (membros de uma quadrilha de assaltantes, que teriam se contaminado pelo uso de drogas intravenosas). Nesta matéria, o portador é igualado àquilo que os criminosos e os loucos representam para a sociedade: um fora-da-lei/fora-da-ordem, marginal e indesejável, que deve ser separado e isolado do convívio social.

Mesmo quando a matéria trata de forma menos pejorativa e preconceituosa as questões da Aids e do portador, como nos dois textos sobre lançamento de livros ("Paixão homossexual é novo tema de Begley" e "As agonias da confissão"), as imagens de dor, sofrimento e tristeza frente à morte não deixam de aparecer a elas associadas. A diferença talvez seja que, nestes casos, os aspectos negativos são revestidos por uma certa beleza poética, uma espécie de sensibilidade artística e talento daqueles que escreveram os livros que tratam sobre a doença. Tem-se a mesma sensação que se tem ao olhar as fotografias de Sebastião Salgado publicadas no livro Terra: o que se vê é miséria, desolação, abandono, mas revestidos de uma beleza estética tão intensa que algo parece fora do lugar. 
Uma série de considerações sobre as matérias em conjunto e a "grande narrativa" nelas contada pôde ser estabelecida, indicando as recorrências encontradas nos quadros figurativos e aquilo a que eles remeteram.

\section{Remetências e recorrências}

Entre os diversos elementos que poderiam ser destacados em termos lingüísticos e narrativos nas matérias analisadas, optou-se, nesse momento, por estabelecer aproximações entre elas a partir de sua organização temática. As matérias foram, dessa forma, agrupadas em três grandes temas - Estado, ciência e homossexualidade -, estes constituindo o que se considerou ser a articulação discursiva da Aids no jornal Folha de S. Paulo. O quadro II apresenta de forma sintética este agrupamento temático.

Note-se que em todos os grupos o discurso da ciência e o discurso do Estado são fundamentais na construção do discurso da Aids. Nas matérias que tratam especificamente de descobertas científicas, pesquisas e medicamentos, o discurso da ciência é predominante. Naquelas relativas a regulamentações em geral (drogas, convênios, direitos dos homossexuais), predomina o discurso do Estado.

As matérias agrupadas no grupo temático Estado compõem, em conjunto, o próprio discurso do Estado, não apenas em relação à Aids mas de forma geral. Nas que se referem aos convênios e às políticas em relação a drogas e saúde pública, por exemplo, fica clara a posição ali representada: o Estado deveria intervir como aquele que ordena e submete, legislando em nome do bem comum.

Em relação à Aids, a principal imagem associada ao Estado é de controle. Nas matérias, aparece como aquele que age e/ou que move a ação, fazendo agir. É o que "analisa”, “define”, “cancela”, “atende”, “repassa”, “cede”, "garante”, “exclui”, "introduz", "resolve", "proíbe".

No grupo temático ciência, nota-se uma predominância de imagens comumente associadas ao discurso religioso, como as de busca, encontro, salvação, esperança. Todas as matérias analisadas nesse grupo (com exceção de duas) referem-se especificamente à questão da Aids, caracterizando o discurso da ciência em relação à doença, mas ao mesmo tempo apontando, em linhas gerais, para os papéis tradicionais da ciência como aquela que realiza descobertas e supera desafios, dominando a natureza. 
Em relação à Aids, a principal imagem associada à ciência é a de cura. Nas matérias, aparece como aquela que "alerta”, "age”, "combate”, "bloqueia”, "realiza”, “faz”, “aplica”, “publica”, “utiliza”, “pesquisa”, “descobre”.

O terceiro grupo temático, homossexualidade, surpreende pela variedade de matérias que engloba. É interessante notar que nas três matérias que fazem referência ao discurso das artes (duas de literatura e uma de cinema) a Aids aparece associada à questão da homossexualidade, por meio dos protagonistas masculinos narrados em livros (um ficcional e o outro autobiográfico) e filme. Três outras matérias fazem referências diretas à questão do homossexualismo $e$ as quatro restantes são variadas. Estas últimas referem-se, principalmente, a atitudes da população em geral em relação a certos eventos ou tendências (como a matéria sobre a copa do mundo ou sobre comportamento sexual dos americanos), a Aids aparecendo nelas como um dado entre outros, e uma delas refere-se especificamente a comportamento de homossexuais masculinos em relação à Aids.

o discurso prevalecente no grupo homossexualidade é o discurso moral, o que estabelece uma certa relação de conjunto entre as matérias nele reunidas. Em relação à Aids, a principal imagem associada aos homossexuais é a de culpa. Nas matérias, aparecem como aqueles que "são presos", "falsificam”, "mantiveram", "relacionam-se”, "sofrem”, “morrem”, “adoecem”, “fazem farra”, “definham”, “pegam”, “passam”, “facilitam”, “contaminam”, “são condenados”, “não usam”. Uma das duas matérias com verbo na forma negativa referia-se aos homossexuais, criticando o não-uso que fazem de preservativos, o que implicaria na disseminação da Aids.

Depois de percorrer o trajeto aqui proposto, a tentativa é de tecer algumas novas relações. A trama deste tecido é trançada mantendo como pano de fundo os três grandes grupos temáticos identificados (Estado, ciência $e$ homossexualidade) para deles fazer uma espécie de "releitura das leituras", tentativa de uma possível conclusão.

\section{Do mal radical e da ciência: narrativas da contemporaneidade}

Jean-François Lyotard inicia e finaliza o texto "Uma fábula pós-moderna" com a seguinte frase: "Como estariam o Humano e seu Cérebro, ou melhor, o Cérebro 
e seu Humano, no momento em que abandonavam o planeta para sempre, antes de sua destruição, isso, a história não dizia” (1996, p.81). Por que estariam, o humano e seu cérebro, ou o cérebro e seu humano, abandonando o planeta? É o próprio Lyotard quem responde:

O Sol vai explodir. Todo o sistema solar, inclusive o pequeno planeta Terra, transforma-se numa grande nova. Quatro bilhões e meio de anos solares transcorreram desde o momento em que essa fábula foi contada. $\mathrm{O}$ final da história já estava previsto a partir desse momento (Lyotard, 1996, p.81).

Lyotard afirma que a única certeza que podemos ter enquanto humanos é que o sol - uma estrela - vai, algum dia, explodir. Estrelas têm vida limitada, e esse tempo pode ser determinado cientificamente. Assim, toda a vida na Terra terá sido organizada no intervalo de tempo transcorrido antes dessa explosão. A fábula contada por Lyotard coloca os humanos, seu planeta e suas realizações como simples produtos de uma força que faz, desfaz e refaz a realidade. Só diz respeito à energia e à matéria como estado da energia, o ser humano sendo uma forma complexa de organização dessa energia. "Nela o homem é considerado um sistema material complexo; a consciência, um efeito de linguagem; e a linguagem, um sistema material muito complexo" (Lyotard, 1996, p.95).

A linguagem é apresentada como um conjunto de "técnicas simbólicas" (as línguas humanas) que permitiram ao sistema Homem, frágil e precário, compensar suas fraquezas perante seus adversários e sobreviver. Compondo elementos entre si, tomando a si própria como objeto, memorizando-se e autocriticando-se, enfim, possibilitando a organização da própria estrutura social dos homens, a linguagem - proposta como estrutura simbólica - é colocada como instituição fundadora do humano.

A fábula pós-moderna, longe de se assemelhar às grandes narrativas propostas pela modernidade (com seus heróis, sua temporalidade histórica, busca de emancipação, esperança no futuro e finalidade), introduz uma diferença essencial desta em relação à contemporaneidade: a necessidade da tecnociência pensar-se a si mesma. Não basta apenas vislumbrar os avanços científicos e tecnológicos realizados até o momento e que continuarão ainda a se realizar até a explosão do sol -, mas, sobretudo, faz-se necessário refletir sobre os usos que deles se farão: 
Quando se pode simular in vitro a explosão solar ou a fecundação $e$ a gestação de um ser vivo, é necessário saber o que se quer. Ora, não temos nenhuma idéia acerca disso. No princípio da varredura, existe esta exclusão dos fins. Ela revestiu-se de todos os disfarces: destino do homem, progresso, luzes, emancipação, felicidade. Hoje, esta exclusão parece completamente nua. Saber e poder mais sim, mas por quê, não (Lyotard, 1990, p.61).

Com o desaparecimento das narrativas especulativas, é a própria modernidade que precisa ser reescrita, não no sentido de ser revista ou refeita, mas de resistir à escrita de uma suposta pós-modernidade que quer se inscrever para inscrevê-la de outro modo. O desaparecimento das grandes narrativas (ao menos em seu sentido clássico) abre espaço para que os arcaísmos e medos mais precários ressuscitem, invocando fantasmas de outrora. A Aids, talvez, seja tão temida por invocar alguns desses fantasmas ancestrais, que voltam à superfície neste momento e que espelham, ao fundo, o medo maior: a morte.

Mas o desaparecimento das grandes narrativas é, ele também, relativo. Retiradas as grandes narrativas tradicionais parece surgir uma outra - ainda que articulando outros sentidos e outra finalidade - que, no limite, não se sabe de forma ainda mais drástica do que as anteriores. A provocação proposta pela fábula ilustra exemplarmente esse "não se pensar": não seriam mais os humanos e seus cérebros a fugirem, mas os cérebros e seus humanos.

O tema das narrativas da contemporaneidade não é nosso objeto específico. Entretanto, é nessa perspectiva que gostaríamos de inserir as reflexões aqui apresentadas, por acreditarmos que as proporções e as configurações que a Aids adquiriu em nossa sociedade têm profunda relação com este nosso tempo/espaço específicos e, portanto, só fazem sentido se nele inscritas. Ao tratar das relações entre o discurso jornalístico e o discurso da Aids, não pode ser esquecido o atual tempo mundo e o atual espaço mundo, e as implicações que essas novas concepções apresentam; é preciso, ao contrário, situar a própria questão da Aids dentro deste quadro.

Cada nova época social está marcada de forma definitiva e particular. É nesse trajeto que se dá a transformação da história e é nessa perspectiva que se inserem as mudanças sociais. Em certos momentos, algo escapa da própria lógica organizativa e se acelera, e este fato é ao mesmo tempo real e irreal. A questão da relação espaço-tempo, nos dias atuais, está marcada por essa aceleração, por 
esse "algo que escapa", desliza, variando de lugar para lugar, de geração para geração, de cultura para cultura.

Inscrevem-se, portanto, processos de desterritorializações e reterritorializações, que reformulam as noções de espaço não mais como espaços físicos mas como espaços imaginários. Criam-se símbolos e signos mundializados que vão formando comunidades imaginárias nas quais os indivíduos passam a se identificar e a se reconhecer, independente de sua procedência ou localização, criando espaços de memória.

Esses "lugares de memória” são definidos por Marc Augé como não-lugares: "Se um lugar pode se definir como identitário, relacional e histórico, um espaço que não pode se definir nem como identitário, nem como relacional, nem como histórico definirá um não-lugar” (Augé, 1994, p.73). A hipótese por ele defendida é a de que a supermodernidade seria formadora de não-lugares. Lyotard fala da criação de "comunidades de sentimentos":

\footnotetext{
Não podemos, de facto, dizer de um sentimento que este deva receber o assentimento de todos sem mediação, i-mediatamente, sem pressupor a existência de um género de comunidade de sentimento, a qual tem o objectivo de fazer com que cada um dos outros indivíduos, colocados diante da mesma situação, a mesma obra, possa, pelo menos, dispor do mesmo julgamento, sem o elaborar conceptualmente (Lyotard, 1990, p.115).
}

Portanto, é nos limites da modernidade-mundo, inscrita nos "lugares de memória”, lugares de imagens fortemente simbólicas, que se instaura um movimento específico mais amplo com relação a valores e aos próprios conceitos de espaço e tempo partilhados pelas pessoas.

Em seu texto La religione (1995), Jacques Derrida apresenta algumas reflexões interessantes para se pensar a idéia do "mal radical" - aqui relacionada à Aids - e da ciência como "salvadora do mal". De acordo com Freitas (1997, p.12), “afastando-se da postura ingênua que opõe Razão e Religião, a Crítica e a Ciência, a Modernidade tecnocientífica e a Religião, Derrida postula que o desenvolvimento imperturbável e interminável da Razão crítica $e$ tecnocientífica, longe de se opor à religião, a sustenta, a suporta e a pressupõe", atribuindo à razão e à religião a mesma fonte. 
Esta associação razão-religião busca, ao mesmo tempo, instaurar o íntegro $e$ o diverso, um não podendo nunca ser escolhido como o único, mas ambos contaminando-se mutuamente. $\mathrm{O}$ autor introduz o termo mundialatinização para sintetizar tal processo. Com esse termo, refere-se a um movimento de latinização do mundo por meio de uma volta ao direito romano e a seus princípios religiosos, como a fé e a crença, ao mesmo tempo que haveria, simultaneamente, um desenvolvimento cada vez mais exponencial daquilo que chama de teletecnociência. A forma como concebe essas relações pode ser assim explicitada:

A mundialatinização, que por seu idioma se torna euro-anglo-americana, é a expressão da indissociabilidade da religião e da razão teletecnocientífica. Contudo, é apenas um dos resultados dessa aliança, pois pela lógica que constrói o discurso de Derrida (a sua pequena máquina discursiva) há um outro lado da religião que reage com todas as suas forças à teletecnociência (Freitas, 1997,p.13).

Assim, a religião, ao mesmo tempo que produz e desfruta o saber e o capital possibilitados pela teletecnociência, reage contra aquilo que lhe dotou de um novo poder, mas que, ao mesmo tempo, pode despojá-la de um lugar que tem sido historicamente seu.

A associação feita por Derrida entre religião e tecnologia pode ser transportada aos termos da oposição doença (Aids) e cura (ciência), de acordo com as matérias anteriormente lidas. É o próprio Derrida quem fornece uma possível conjugação destes termos:

\footnotetext{
Como desejar novas luzes para explicar esse "retorno do religioso" sem articular pelo menos uma lógica qualquer do inconsciente? Sem refletir, pelo menos, sobre a questão do mal radical, da reação ao mal radical no centro do pensamento freudiano? (...) Mas também, mais do que nunca, contra-fetichismo do mesmo desejo invertido, a relação animadora com a máquina teletecnocientífica que se torna, portanto, máquina do mal, e do mal radical, máquina de manipular, assim como de exorcizar. Porque há o mal a ser domesticado e porque hoje se "utilizam" sempre mais artefatos e próteses dos quais ignora-se tudo, numa crescente desproporção entre SABER e HABILIDADE, o espaço dessa experiência técnica tende a se tornar cada vez mais animista, mágico e mítico (Derrida, 1995, p.62).
} 
A contemporaneidade, portanto, reveste-se de elementos cada vez mais míticos pela desproporção que se estabelece entre o que se conhece e o que se sabe. Em linhas gerais, trata-se de um profundo desconhecimento em relação às novas tecnologias e aos objetos usados no cotidiano, funcionando da mesma forma que o fanatismo religioso ao criar o obscurantismo, o mítico, o mistério, o desconhecido. A Aids enquanto doença parece ser já bastante conhecida (a questão da informação), mas dela pouco se sabe (e é essa a busca incessante da ciência).

A ciência - em relação à Aids - parece estar articulada como uma espécie de religião. Conserva, portanto, todas as características de uma religião, o que não quer dizer que haja uma substituição da religião como fé em Deus pela religião como culto à ciência (ou à teletecnociência de Derrida); há, sim, pontos de contato entre os dois processos (a religião e a ciência), principalmente no que se refere ao mistério - ligado a um não-saber - e à crença - crer mesmo sem conhecer. Não se trata, é necessário reafirmar, de estabelecer a ciência como uma nova religião (mesmo porque tal relação com a ciência, em se ampliando a questão para além da Aids, não é nova), mas sim de dizer que este processo está articulado como uma religião.

Em relação à Aids, isso implica que, além de a ciência agir permanentemente em busca da cura - uma espécie de redenção -, projeta-se nela uma certa esperança: espera-se que traga a salvação, operando um milagre - a eliminação da doença.

Esse processo de "nova religião" se dá no contexto das novas tecnologias da comunicação, que produzem reflexos na vida social, cultura, educação, usos cotidianos, profissionalização, e não apenas em relação à saúde. Parece pertinente estabelecer aqui o contato com as leituras das matérias: como a questão da Aids (enquanto "boa notícia" da ciência divulgada pelos jornais) insere-se nesse quadro da teletecnociência como religião? Que efeitos essa "religião" engendra nos modos de escrever, dar a conhecer a Aids?

Ao organizar-se enquanto narrativa instituída pelo discurso, o imaginário sobre a Aids passa a impregnar o simbólico, velando-o. $\mathrm{O}$ ar de mistério e incompreensão pelo que não se pode controlar manifesta-se também aqui, apontando, talvez, para o desgaste das grandes narrativas, que não conseguiriam mais sustentar esse mesmo imaginário construído, desfazendo-se. Poderíamos 
associar a Aids à teletecnociência, à informatização, constituindo-a na mesma direção dos grandes males, algo a ser temido ou até mesmo combatido, o mal radical que nos ameaçaria desde sempre, temor acentuado pelo ainda desconhecimento que a cerca.

Apesar de conhecer como ela se dá ao contágio (como se pode "pegá-la"), ainda não se sabe como dominá-la e controlá-la: a Aids captura os corpos e os submete a sua vontade, já que não se sabe nem ao menos quando virá seu "ataque final", a passagem do vírus de "inativo" para "ativo". Talvez se possa até mesmo dizer que a Aids se articula com uma dupla configuração: como um fenômeno extremamente contemporâneo mas que, ao mesmo tempo, evoca as coisas mais arcaicas, a própria religio de Derrida.

Dentro dessa dinâmica de configuração do discurso da Aids, os media teriam papel fundamental pela possibilidade de "distribuir" a todo o planeta imagens da doença. É de Edward Said o conceito de formação de comunidades imaginárias (ou virtuais) a partir dos media. Ao mesmo tempo que há um movimento de desterritorialização das culturas, isto é, rompem-se os antigos conceitos de tempo/espaço, rompe-se a antiga divisão de nações/países/primeiro e terceiro mundos, estes conceitos são recriados de novas formas, com novas organizações.

Nesse processo, os media ocupariam um lugar importante: “(...) o sistema internacional dos media realizou de fato o que noções de coletividade de inspiração idealista ou ideológica - comunidades imaginárias - aspiravam fazer" (Said, 1993, p.309). Ou seja: as construções narrativas dos media - sua forma de contar o mundo por meio da seleção de histórias, palavras e imagens, $e$ de sua rearticulação discursiva - contribuíram significativamente para a criação $e$ articulação dessas comunidades imaginárias, seja por meio de jornais impressos, revistas internacionais, noticiários televisivos ou notícias divulgadas via Internet. Isso foi possível, principalmente, graças ao fato dos media não serem apenas "uma rede prática completamente integrada, mas um modo extremamente eficiente de articulação costurando o mundo em um só" (Said, 1993, p.309).

Esse sistema mediático, mundialmente estabelecido, ao articular e produzir um tipo de poder cultural, econômico e político, associado a seus desdobramentos militares e demográficos, "tem uma tendência institucional de produzir em grande escala imagens transnacionais que estão agora reorientando 
o processo e o discurso social internacionais" (Said, 1993, p.309). Se considerarmos tal possibilidade, a Aids poderia ser incluída como sendo uma dessas imagens transnacionais orientando o discurso internacional.

A Aids caracteriza exemplarmente a contemporaneidade, seja na forma da mundialatinização de Derrida, seja nas menos pessimistas comunidades imaginárias de Said. Trata-se de uma epidemia de proporções planetárias, atingindo indistintamente todos os países do mundo, ainda que tenha características específicas em cada um deles. Mais do que isso, cria uma cultura também mundial sobre si mesma, fundamentalmente marcada pelo pânico e pelo medo. As imagens que evoca sobre si parecem não se diferenciar de modo radical de um país a outro, podendo-se dizer que narrativas também mundializadas passam a ser construídas em relação a ela.

Dessa doença, de proporções tão vastas tanto do ponto de vista do atingimento do corpo presente (veja-se o caso de Magic Johnson) como ausente - mas implícito em termos de construções simbólicas -, pode-se mesmo dizer que é parte indissociável do próprio processo de rearticulação da contemporaneidade. É o mal contra o qual se luta, ou em relação ao qual se desvia o olhar. Metáfora presente nos males que assolam a humanidade hoje, o mundo contemporâneo.

Não é possível pensar a Aids e suas características específicas sem pensar no tempo-espaço atual, já que esta doença parece romper os limites dos termos médico-científicos ou da complexidade de seu vírus causador (um vírus chamado por alguns pesquisadores de "inteligente" devido a sua capacidade de adaptação a novos medicamentos, neutralizando seus efeitos). Mais do que uma doença complexa do ponto de vista médico-científico e da saúde dos indivíduos contaminados, a Aids também se mostra como extremamente complexa do ponto de vista imaginário e simbólico.

Mesmo apresentando em si elementos comuns a outras doenças antes vistas como os grandes "males" da humanidade (caso da sífilis, da peste negra, da tuberculose, por exemplo), a Aids potencializou como nunca havia acontecido antes a marca de uma doença mortal - colocado aqui todo o peso dessa palavra. Em grande parte, isso se deve ao fato de relacionar elementos universalmente perturbadores e polêmicos na história da humanidade - o sexo e a morte -, como pôde ser percebido na leitura das matérias. 
Enquanto narrativa incluída na grande narrativa da contemporaneidade, a Aids reveste-se de todas essas características e contradições, configurando uma espécie de confluência de algo, a princípio, paradoxal: o futuro e o passado, o homem-a-ser e seus ancestrais.

\section{Uma grande narrativa: discurso}

Haveria realmente no discurso sobre a Aids a relação entre o "mal radical", por um lado, e a "ciência", por outro? As matérias analisadas, publicadas na Folha de S. Paulo, parecem apontar para uma certa correlação entre esses dois aspectos e as narrativas da Aids.

Os três temas apontados - Estado, ciência e homossexualidade - poderiam reduzir-se a dois grandes temas, fundantes da quase totalidade das narrativas clássicas: o "bem" e o "mal”, a ciência e a Aids. A ciência, apresentada aqui como concebida por Derrida enquanto revestida de um modo de operação semelhante ao da religio, apareceria, então, como promessa e redenção. A ciência "bloqueia", "pesquisa”, "encontra”, "busca”.

A Aids, por sua vez, a partir dos elementos destacados nas matérias - em sua relação de significantes considerados em articulação com outros elementos significantes enquanto estrutura da atividade simbólica (Lacan, 1995) - aparece como o mal radical do qual fala Derrida. A Aids "submete", "definha", "vinga", "agoniza". Ao doente, promete-se a cura, o recebimento de uma espécie de bênção, a sanção positiva.

Principalmente nos textos que tratam da questão das drogas e da homossexualidade, em suas múltiplas e diversas aparições, a idéia de "mal” está sempre presente. Nas matérias "Zurique quer deixar de ser centro de drogas" e "Justiça italiana caça imunidade penal de aidético", por exemplo, a postura é de recriminação aos usuários de drogas e a Aids surge como uma espécie de "castigo" a eles imposto devido aos "pecados" que cometeram (note-se que o discurso religioso impregna as relações imaginárias aqui estabelecidas).

Na questão da homossexualidade, por sua vez, como nas matérias "Inglês é preso por falsificar documentos de namorado" e "Sedes se preparam para festival erótico", o enfoque é notadamente tendencioso e preconceituoso em relação aos homossexuais. $\mathrm{O}$ "inglês falsificador e gay" também teve o castigo que merecia, dentro da normalidade da lei: foi condenado à prisão.

Entretanto, alguns textos deixam entrever possibilidades diversas. $\mathrm{O}$ mesmo jornal que publicou as matérias acima citadas traz imagens divergentes, 
apontando outras interpretações. Em relação às drogas, as matérias "Novos rumos na política de drogas alemã" e "Preconceito também mata" humanizam o usuário de drogas e buscam revesti-lo de elementos de individualidade e cidadania. Quanto à homossexualidade, a matéria "Os gays e a visita do papa", principalmente, busca estabelecer uma relação de aparente equilíbrio e normalidade aos que chama de "amantes do mesmo sexo". Brechas entreabertas, flutuações significantes, já que estes têm como jogo fundamental a permutação (Lacan, 1995).

Nas tramas flutuantes/fluentes dos significantes, nas cadeias que se entrelaçam e se desfazem, há sempre elementos novos, que não podem deixar de ser considerados uns em relação aos outros. Recentemente, lendo uma matéria publicada na Folha de S. Paulo, alguém comentou: "É estranho, mas parece que a Folha quer de todo jeito que as mulheres ultrapassem os homens em casos de Aids". A frase pedia que se fosse conferi-la.

Ao verificar matérias publicadas em 1997 na Folha de S. Paulo sobre a infecção pelo HIV entre mulheres, constatou-se que fazia sentido. É claro que não se pode negar o aumento em escala geométrica, diversas vezes confirmado por meio de pesquisas, do número de mulheres infectadas. Entretanto, as manchetes do jornal tratam o tema como se fosse simples estatística, um resultado de pesquisa eleitoral: "O candidato $X$ supera o candidato $Y$ em $5 \%$ dos votos". Observe-se as seguintes manchetes, publicadas na seção Saúde do caderno São Paulo, em 26 de julho de 1997: "Recuo da epidemia da Aids é menor para as mulheres" (chapéu: "Queda de mortes de homens foi 5 vezes maior que a de mulheres no $2^{\circ}$ semestre”); “Aumenta transmissão de mãe para filho" (chapéu: "Crescimento da infecção de mulheres causa maior número de bebês portadores; mães não sabem que têm o vírus").

Retomando a relação bem/mal nas matérias sobre drogas e sobre homossexualidade, uma interessante conexão pode ser ensaiada: abertas as passagens para que "drogados" e "gays" fossem constituídos no discurso jornalístico como pessoas não tão "maléficas" assim, o grande vilão a canalizar a figura do "mal" nas narrativas sobre a Aids parece ser a mulher. Remetendo tal imagem ao discurso religioso que parece permear tanto as matérias da "redentora ciência" como as da "amaldiçoada doença", encontra-se a mulher como uma figura comumente associada à maledicência, à danação. Não foi à toa que as bruxas foram queimadas durante a Inquisição.

Nos deslizamentos significantes, a imagem-imaginária do "mal” parece deslizar, agora, para a mulher, constituindo-a de outra forma, pela linguagem, no discurso da Aids. O percurso desses deslizamentos é incessante, inesgotável mesmo. $O$ discurso, laço social, não se cerra/encerra nunca: constitui-se em permanente escritura. 


\begin{tabular}{|c|c|c|}
\hline \multicolumn{3}{|c|}{ QUADRO I - MATÉRIAS DIA A DIA } \\
\hline Dia & \multicolumn{2}{|c|}{ Título } \\
\hline 03/01/94 (2a feira) & \multicolumn{2}{|c|}{ Atualidade determina o preço de ser feliz } \\
\hline & \multicolumn{2}{|l|}{ A pilula não é pra todos } \\
\hline 08/03/94 (3a feira) & \multicolumn{2}{|c|}{ Câmara analisa projeto para plano de saúde } \\
\hline 16/03/94 (4ª feira) & \multicolumn{2}{|c|}{ Ministro define regra para convênio médico } \\
\hline & \multicolumn{2}{|l|}{ Filmes ironizam convênios de saúde } \\
\hline 28/04/94 (5 feira) & \multicolumn{2}{|c|}{ Inlgês é preso por falsificar documentos do namorado } \\
\hline & \multicolumn{2}{|l|}{ Xuxa diz que aceita fazer teste de HIV } \\
\hline 06/05/94 (6 feira) & \multicolumn{2}{|c|}{ Água pode transmitir infecção a aidéticos } \\
\hline 11/06/94 (sábado) & \multicolumn{2}{|l|}{ Sedes se preparam para festival erótico } \\
\hline 17/07/94 (domingo) & \multicolumn{2}{|c|}{ Paixão homossexual é novo tema de Begley } \\
\hline 23/08/94 (3ª feira) & \multicolumn{2}{|c|}{ Morango e chocolate vinga sonho tropical } \\
\hline 13/10/94 (5 feira) & \multicolumn{2}{|c|}{ Sexo exótico perde fôlego na Gringolândia } \\
\hline 24/12/94 (sábado) & \multicolumn{2}{|l|}{ Preconceito também mata } \\
\hline 14/02/95 (3 feira) & \multicolumn{2}{|c|}{ Zurique quer deixar de ser centro de drogas } \\
\hline 15/03/95 (4ª feira) & \multicolumn{2}{|c|}{ Novo convênio cobre terapias alternativas (box) } \\
\hline & \multicolumn{2}{|c|}{ Produtora carioca é a $1^{\text {a }}$ voluntária a se submeter à vacina anti-Aids } \\
\hline 09/04/95 (domingo) & \multicolumn{2}{|c|}{ Novos rumos na política de drogas alemã } \\
\hline & \multicolumn{2}{|c|}{ Bispo anglicano defende sacerdotes homossexuais (entrevista) } \\
\hline & \multicolumn{2}{|c|}{ As agonias da conifssão } \\
\hline 05/05/95 (6ª feira) & \multicolumn{2}{|l|}{ Falta paz na saúde em São Paulo } \\
\hline 10/06/95 (sábado) & \multicolumn{2}{|l|}{ Exame de audição pode detectar HIV } \\
\hline 17/07/95 ( $2^{\mathrm{a}}$ feira) & \multicolumn{2}{|c|}{ Falta de voluntários atrasa pesquisa de Aids } \\
\hline 06/09/95 (4a feira) & \multicolumn{2}{|c|}{ Brasileiros (quem diria) anunciam cura da Aids } \\
\hline & Doente grave deve receber nova dro & contra HIV \\
\hline & Os gays e a visita do papa & \\
\hline $22 / 10 / 95$ (domingo) & Justiça italiana caça imunidade penal & aidético \\
\hline $17 / 11 / 95$ (6 feira) & Substância bloqueia "Aids de macaco & \\
\hline & Ser unicelular pode ativar HIV & \\
\hline 23/12/95 (sábado) & Pacientes fogem de médicos no fim $d$ & no \\
\hline & $47 \%$ dos gays não usam preservativo & box) \\
\hline & Fiocruz vai ter hospital para tratar a & ticos \\
\hline & QUADRO II - MATÉRIAS POR TEMAS & \\
\hline ESTADO & CIÊNCIA & HOMOSSEXUALIDADE \\
\hline $\begin{array}{l}\text { Câmara analisa projeto para } \\
\text { plano de saúde (08/02/94) }\end{array}$ & $\begin{array}{l}\text { Atualidade determina o preço } \\
\text { de ser feliz (03/01/94) }\end{array}$ & $\begin{array}{l}\text { Inglês é preso por falsificar } \\
\text { documentos de namorado } \\
(28 / 04 / 94)\end{array}$ \\
\hline $\begin{array}{l}\text { Ministro define regra para } \\
\text { convênio médico }(16 / 03 / 94)\end{array}$ & $\begin{array}{l}\text { A pílula não é para todos } \\
(03 / 01 / 94)\end{array}$ & $\begin{array}{l}\text { Sedes se preparam para } \\
\text { festival erótico }(11 / 06 / 94)\end{array}$ \\
\hline $\begin{array}{l}\text { Filmes ironizam convênio de } \\
\text { saúde }(16 / 03 / 94)\end{array}$ & $\begin{array}{l}\text { Água pode transmitir infecção a } \\
\text { aidéticos }(06 / 05 / 94)\end{array}$ & $\begin{array}{l}\text { Paixão homossexual é novo } \\
\text { te,a de Belgey (17/07/94) }\end{array}$ \\
\hline $\begin{array}{l}\text { Xuxa diz que aceita fazer } \\
\text { teste de HIV }(28 / 04 / 94)\end{array}$ & $\begin{array}{l}\text { Produtora carioca é a } 1^{\text {a }} \\
\text { voluntária a se submeter à } \\
\text { vacina anti-Aids }(15 / 03 / 95)\end{array}$ & $\begin{array}{l}\text { "Morango e chocolate" vinga } \\
\text { sonho tropical }(23 / 08 / 94)\end{array}$ \\
\hline $\begin{array}{l}\text { Preconceito também mata } \\
(24 / 12 / 94)\end{array}$ & $\begin{array}{l}\text { Exame de audição pode } \\
\text { Detectar HIV (10/06/95) }\end{array}$ & $\begin{array}{l}\text { Sexo exótico perde fogo na } \\
\text { Gringolândia (13/10/94) }\end{array}$ \\
\hline $\begin{array}{l}\text { Zurique quer deixar de ser } \\
\text { centro de drogas }(14 / 02 / 95)\end{array}$ & $\begin{array}{l}\text { Falta de voluntários atrasa } \\
\text { pesquisa de Aids (17/07/95) }\end{array}$ & $\begin{array}{l}\text { Bispo anglicano defende } \\
\text { sacerdotes homossexuais } \\
\text { (09/04/95) }\end{array}$ \\
\hline $\begin{array}{l}\text { Novos rumos na política de } \\
\text { drogas alemã (09/04/95) }\end{array}$ & $\begin{array}{l}\text { Doente grave deve receber } \\
\text { nova droga contra HIV } \\
\text { 06/09/95) }\end{array}$ & $\begin{array}{l}\text { Os gays e a visita do papa } \\
(06 / 09 / 95)\end{array}$ \\
\hline $\begin{array}{l}\text { Falta paz na saúde de São } \\
\text { Paulo (05/05/95) }\end{array}$ & $\begin{array}{l}\text { Substância bloqueia "Aids de } \\
\text { macacos" (17/11/95) }\end{array}$ & $\begin{array}{l}\text { Pacientes fogem de médicos } \\
\text { no final do ano }(23 / 12 / 95)\end{array}$ \\
\hline $\begin{array}{l}\text { Justiça italiana caça } \\
\text { imunidade penal de aidético } \\
(22 / 10 / 95)\end{array}$ & $\begin{array}{l}\text { Ser unicelular pode ativar HIV } \\
(17 / 11 / 95)\end{array}$ & $\begin{array}{l}47 \% \text { dos gays não usam } \\
\text { preservativos }(23 / 12 / 95)\end{array}$ \\
\hline $\begin{array}{l}\text { Fiocruz vai ter hospital para } \\
\text { tratar aidéticos }(23 / 12 / 95)\end{array}$ & & \\
\hline
\end{tabular}


Referência bibliográficas

AUGÉ, M. Não-lugares: introdução a uma antropologia da supermodernidade. Campinas: Papirus, 1994 (col. Travessia do Século).

BARTHES, R. O rumor da língua. São Paulo: Brasiliense, 1988.

BENVENISTE, E. Problemas de lingüística geral II. Campinas: Pontes, 1989.

BIANCARELLI, A. Doença em foco: as reportagens sobre Aids publicadas pela

Folha de S. Paulo. Revista USP, São Paulo, n.33, mar./abr./maio 1997.

DERRIDA, J. La Religione. Bari: Annuario Filosofico Europeo, Biblioteca di Cultura Moderna Laterza, 1995.

FREITAS, J. M. M. A CNN e a globalização mediática: uma nova hegemonia ou a formação de comunidades imaginárias?. A globalização da comunicação. A desterritorialização da cultura. A tecnologia. Projeto de Extensão da Pesquisa. São Paulo, Escola de Comunicações e Artes, Departamento de Jornalismo e Editoração/CNPQ, 1997.

GANS, H. Deciding what's news. New York: Vintage Books, 1980.

HADDAD, S. (org.). Aids, juventude, educação: catálogo de fontes de informação e materiais educativos. São Paulo: Cedi, 1993.

LACAN, J. Ecrits. Paris: Seuil: 1966. Mais, ainda. O Seminário, livro 20. 2a ed. São Paulo: Jorge Zahar, 1985. A relação de objeto. O Seminário, livro 4. Rio de Janeiro: Jorge Zahar, 1995.

LÉVI-STRAUSS, C. Introdução à obra de Marcel Mauss. In: MAUSS, M. Sociologia e Antropologia. v. I. São Paulo: EPU/Edusp, 1974.

LYOTARD, J.-F. O inumano: considerações sobre o tempo. Lisboa: Estampa, 1990 (col. Margens).

LYOTARD, J.-F. Moralidades pós-modernas. Campinas: Papirus, 1996 (col.

Travessia do Século).

SAID, E. Culture and imperialism. New York: A. Knopf, 1993.

SCHUDSON, M. The power of news. Cambridge: Harvard University Press, 1995. SONTAG, S. Assim vivemos agora. São Paulo: Companhia das Letras, 1995. 


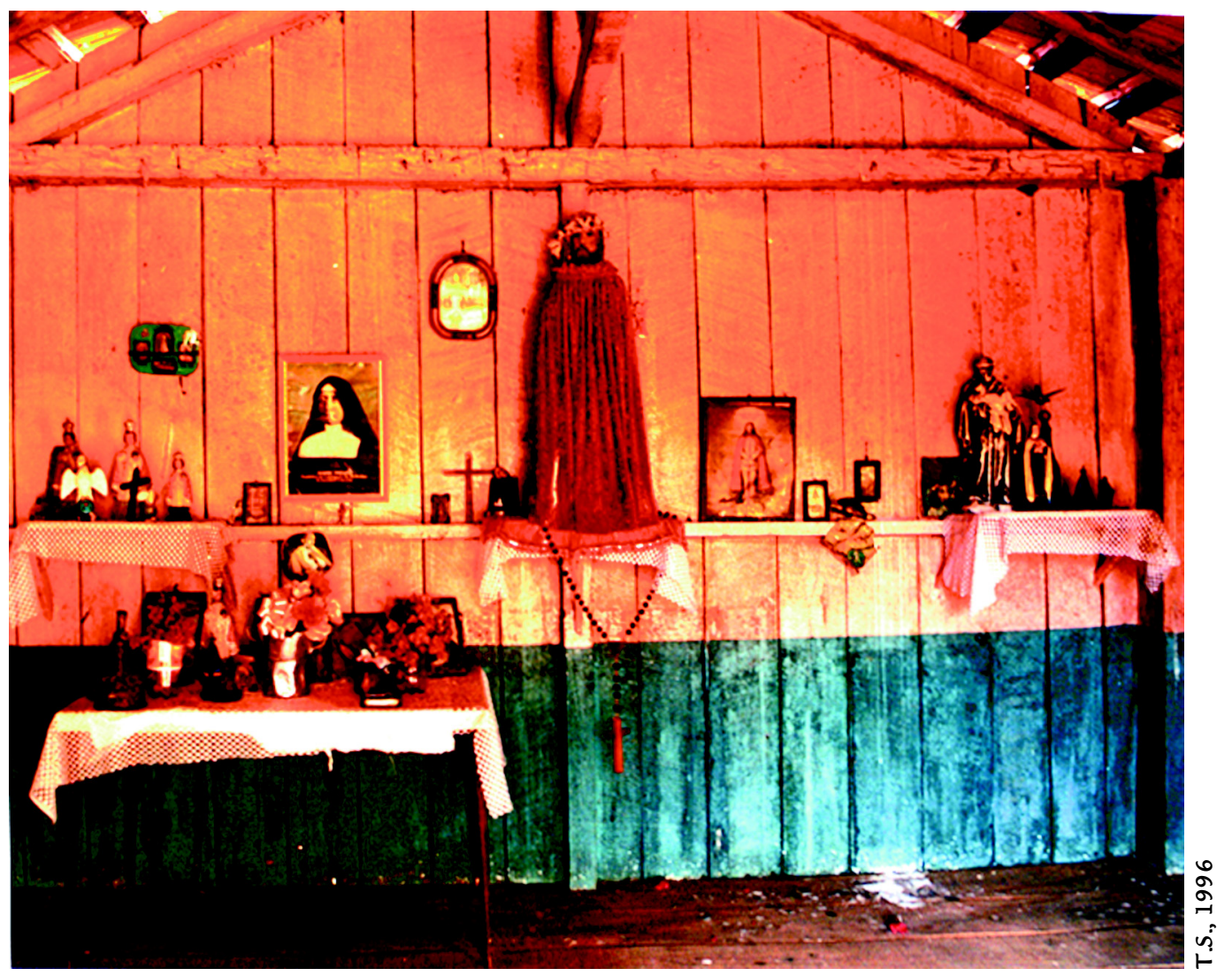


O desenvolvimento impertubável $e$

interminável da razão crítica $e$

tecnocientífica, longe de se opor à religião, a sustenta $e$ a pressupõe.

DERRIDA 